\title{
An anatomical study of medial epicondyle in relation with nerves
}

\author{
Mangesh Santram Selukar ${ }^{1}$, Geetanjali Bhagwanrao Sudke ${ }^{2 *}$
}

${ }^{1}$ Deputy Dean Cum HOD \& Associate Professor, ${ }^{2}$ Assistant Professor, Department of Anatomy, V D Government Medical College, Latur, Maharashtra, 413512, INDIA.

Email: mangesh70201@rediffmail.com, drsudkegeeta@gmail.com

\section{$\underline{\text { Abstract }}$}

\begin{abstract}
Background: Cubital tunnel syndrome, or ulnar nerve compression at the elbow, is the second most common compression neuropathy after carpal tunnel syndrome. Aims and Objectives: To study anatomy of the medial epicondyle in relation with nerves. Methodology: This was a cadaveric study in the 36 cadaveric hand dissected in the department of anatomy of V D Government Medical College, Latur during the two year duration i.e. January 2019 to January 2021, in the 2 years duration all the cadavers are dissected carefully and the observations were noted in the excel sheet. Data was entered in the Microsoft excel for windows 10 software and calculated Mean and Standard deviation. Result: In our study, Arm length (cm) was $28.12 \pm 2.34$; Length of Arcade of Struthers (AS) $(\mathrm{cm})$ was $4.12 \pm 1.65$ Distance between AS and Medial epicondyle was $8.62 \pm 0.98$. Average branching pattern of nerve related to medial epicondyle i.e. for Median nerve branching (Mean $\pm \mathrm{SD}$ ) - $3.1 \pm 0.94$; Radial nerve branching (Mean $\pm \mathrm{SD}$ ) -2.28 \pm 1.02 ; Ulnar nerve branching $(\mathrm{Mean} \pm \mathrm{SD})$ $2.91 \pm 0.59$ respectively. Conclusion: An anatomical study of medial epicondyle in relation with nerves not only important for the prevention of pathologies of elbow but also helpful in the treatment of the fractures of lower end of humerus and medical epicondyle.

Key word: Medial epicondyle, Arcade of Struthers, ulnar nerve compression.
\end{abstract}

*Address for Correspondence:

Dr Geetanjali Bhagwanrao Sudke, Assistant Professor, Department of Anatomy, V D Government Medical College, Latur- 413512, INDIA.

Email: drsudkegeeta@gmail.com

Received Date: 26/02/2021 Revised Date: 24/03/2021 Accepted Date: 16/04/2021

DOI: https://doi.org/10.26611/10011822

This work is licensed under a Creative Commons Attribution-NonCommercial 4.0 International License. $(\boldsymbol{c c})$ EY-NC

\begin{tabular}{|l|l|}
\hline \multicolumn{2}{|c|}{ Access this article online } \\
\hline Quick Response Code: & Website: \\
\hline & www.medpulse.in \\
\hline
\end{tabular}

\section{INTRODUCTION}

Cubital tunnel syndrome, or ulnar nerve compression at the elbow, is the second most common compression neuropathy after carpal tunnel syndrome ${ }^{1}$. Whatever causes the cubital tunnel to shorten or the pressure on the ulnar nerve to rise, the blood supply to the ulnar nerve can be reduced directly or indirectly, resulting in peripheral nerve entrapment syndrome. Patients with cubital tunnel syndrome frequently experience secondary symptoms such as ulnar nerve paresthesia and weakening or atrophy of the hand's intrinsic musculature ${ }^{2,3}$. Cubital tunnel syndrome is difficult to diagnose because there is no gold standard. When conservative treatments for cubital tunnel syndrome have failed, surgical therapy is recommended. ${ }^{4}$ In situ decompression, subcutaneous transposition, intramuscular transposition, medial epicondylectomy, and anterior transposition are all common surgical procedures. ${ }^{3}$ Decompression and anterior transposition of the ulnar nerve are the most often used surgical methods among these treatments. ${ }^{5}$ When conducting anterior transposition of the vascularized ulnar nerve, however, protecting the ulnar nerve's blood supply and limiting the appropriate distance that the ulnar nerve is transposed anteriorly are crucial $^{7}$. Many published research in the literature are now divided on how to best protect the ulnar nerve's blood supply and how far the nerve should be anteriorly transferred. The goal of this study was to monitor and measure the ulnar nerve and its blood vessels at the elbow, as well as to simulate anterior transposition of the vascularized ulnar nerve, in order to establish the most optimal distance that the ulnar nerve should be transposed. 


\section{METHODOLOGY}

This was a cadaveric study in the 36 cadaveric hand dissected in the department of anatomy of $\mathrm{V} D$ Government Medical College, Latur during the two year duration i.e. January 2019 to January 2021, in the 2 years duration all the cadavers dissected carefully and the observations were noted in the excel sheet. All the observations were measured by vernier caliper. In our study we have focused on the anatomical study of medical epicondyle and its associated important anatomical structures like Arm length $(\mathrm{cm})$ Length of Arcade of Struthers, Distance between AS and Medial epicondyle, branching pattern of nerve related to medial epicondyle, Median nerve branching, Radial nerve branching, Ulnar nerve branching. Data was entered in the Microsoft excel for windows 10 software and calculated Mean and Standard deviation.

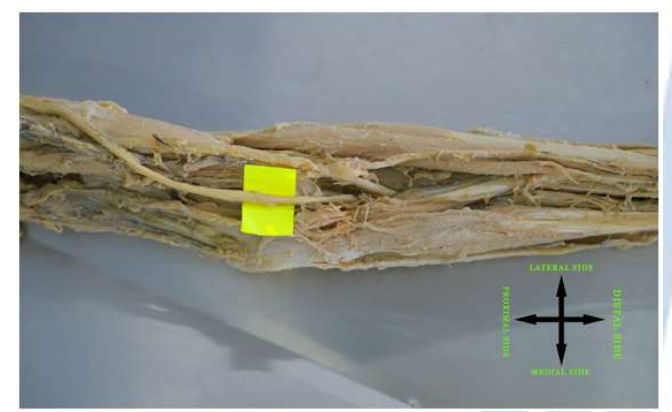

Figure 1: Median nerve dissected near medial epicondyle

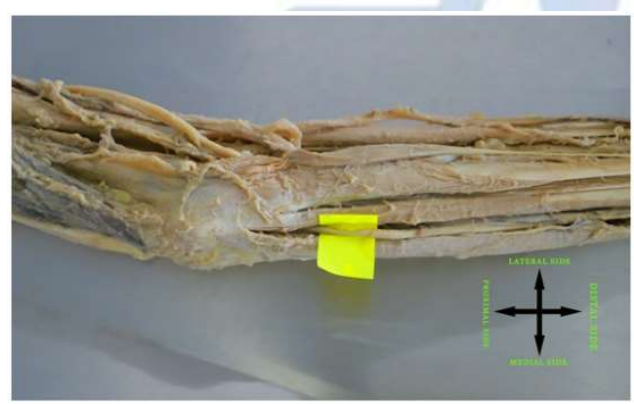

Figure 2: Uinar nerve dissected near medial epicondyle

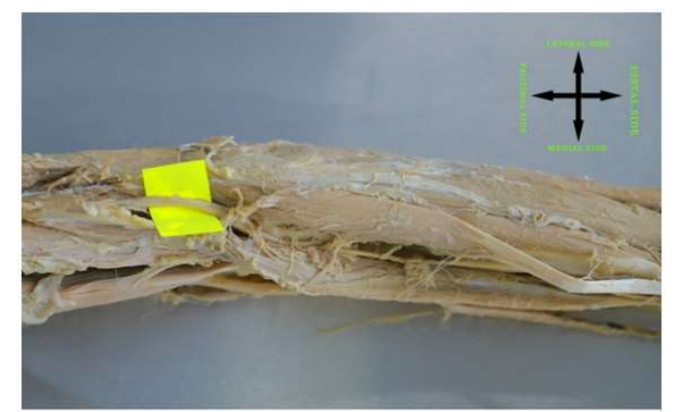

Figure 3: Redial nerve dissected near medial epicondyle
Table 1: Distribution of the parameters related to medial epicondyle $(n=36)$

\begin{tabular}{cc}
\hline Parameter & Mean \pm SD \\
\hline Arm length (cm) & $28.12 \pm 2.34$ \\
Length of Arcade of Struthers (AS) (cm) & $4.12 \pm 1.65$ \\
Distance between AS and Medial epicondyle & $8.62 \pm 0.98$ \\
\hline
\end{tabular}

Arm length (cm) was: $28.12 \pm 2.34$; Length of Arcade of Struthers (AS) $(\mathrm{cm})$ was: $4.12 \pm 1.65$; Distance between AS and Medial epicondyle was: $8.62 \pm 0.98$.

Table 2: Distribution of branching pattern of nerve related to medial epicondyle $(n=36)$

\begin{tabular}{|c|c|c|}
\hline $\begin{array}{c}\text { Median nerve } \\
\text { branching } \\
\text { (Mean } \pm \text { SD) }\end{array}$ & $\begin{array}{c}\text { Radial nerve } \\
\text { branching } \\
\text { (Mean } \pm \text { SD) }\end{array}$ & $\begin{array}{c}\text { Ulnar nerve } \\
\text { branching } \\
\text { (Mean } \pm \text { SD) }\end{array}$ \\
\hline $3.1 \pm 0.94$ & $2.28 \pm 1.02$ & $2.91 \pm 0.59$ \\
\hline
\end{tabular}

Average branching pattern of nerve related to medial epicondyle i.e. for Median nerve branching (Mean \pm SD) $3.1 \pm 0.94$; Radial nerve branching (Mean \pm SD) $-2.28 \pm$ 1.02; Ulnar nerve branching (Mean \pm SD)- $2.91 \pm 0.59$ respectively.

\section{DISCUSSION}

Kane was the first to characterise the "arcade of Struthers" as the thickening of the distal arm's deep investing fascia and superficial triceps muscle fibres that extend to the medial intermuscular septum in 1973. The roof was characterised as the thickening deep fascia of the distal region of the arm, which extended to the medial intermuscular septum and was related to the internal brachial ligament. The medial intermuscular septum formed the anterior wall. The deep fibres of the medial head of the triceps muscle served as the floor. ${ }^{10}$ However, the prevalence of this structure has been shown to range from $1 \%$ to $100 \%$ in numerous studies. ${ }^{9,1011}$ A secondary compression of the ulnar nerve after anterior transposition surgeries has been described in various investigations, causing ulnar never compression symptoms in patients. ${ }^{12-}$ ${ }^{13}$ The medial intermuscular septum and the arcade of Struthers were two common compression sites. ${ }^{8,12-13}$ In our study we have seen Arm length (cm) was $28.12 \pm 2.34$; Length of Arcade of Struthers (AS) (cm) was $4.12 \pm 1.65$ Distance between AS and Medial epicondyle was $8.62 \pm$ 0.98. Average branching pattern of nerve related to medial epicondyle i.e. for Median nerve branching (Mean \pm SD) $3.1 \pm 0.94$; Radial nerve branching (Mean \pm SD) $-2.28 \pm$ 1.02; Ulnar nerve branching (Mean $\pm \mathrm{SD}$ )- $2.91 \pm 0.59$ respectively which was similar to Piyapong Tiyaworanan 14 et al. they found The distance between the greater tuberosity and the lateral epicondyle was designated as the arm length. The arcades of Struthers were identified in $85.4 \%$. The mean arm length was $27.85 \pm 1.3 \mathrm{~cm}$. The mean of the distance between proximal border of the arcade of Struthers and the medial humeral epicondyle was $8.24 \pm$ 2:06 cm. 


\section{CONCLUSION}

An anatomical study of medial epicondyle in relation with nerves not only important for the prevention of pathologies of elbow but also helpful in the treatment of the fractures of lower end of humerus and medical epicondyle.

\section{REFERENCES}

1. Contreras MG, Warner MA, Charboneau WJ, Cahill DR (1998) Anatomy of the ulnar nerve at the elbow: potential relationship of acute ulnar neuropathy to gender differences. Clin Anat 11:372-378.

2. Mitsionis GI, Manoudis GN, Paschos NK, Korompilias AV, Beris AE (2010) Comparative study of surgical treatment of ulnar nerve compression at the elbow. J Shoulder Elbow Surg 19:513-519.

3. Palmer BA, Hughes TB (2010) Cubital tunnel syndrome. J Hand Surg Am 35:153-163.

4. Sugawara M (1988) Experimental and clinical studies of the vascularized anterior transposition of the ulnar nerve for cubital tunnel syndrome. Nihon Seikeigeka Gakkai Zasshi 62:755-766.

5. Bartels RH (2001) History of the surgical treatment of ulnar nerve compression at the elbow. Neurosurgery 49:391-400.

6. Ochi K, Horiuchi $\mathrm{Y}$, Nakamura $\mathrm{T}$, Sato $\mathrm{K}$, Arino $\mathrm{H}$, Koyanagi $T$ (2013) Ulnar nerve strain at the elbow in patients with cubital tunnel syndrome: effect of simple decompression. J Hand Surg Eur Vol 38:474- 480.
7. Zhou JL, Du RX, Wang QY, Liu QH, Meng XL, Wang ZW (2005) Anatomic and clinical study of anterior transposition of the vascularized ulnar nerve for cubital tunnel syndrome. Zhongguo Linchuang Jiepou Xue Zazhi 23:484-486.

8. Ochiai N, Hayashi T, Ninomiya S, High ulnar nerve palsy caused by the arcade of Struthers, J Hand Surg Br 17:629631, 1992.

9. Gonzalez MH, Lotfi P, Bendre A, Mandelbroyt Y, Lieska $\mathrm{N}$, The ulnar nerve at the elbow and its local branching: an anatomical study. J Hand Surg Br 26:142144, 2001

10. De Jesus R, Dellon AL, Historic origin of the $\backslash$ Arcade of Struthers", J Hand Surg Am 28:528531, 2003.

11. Al-Qattan MM, Murray KA, The arcade of Struthers: an anatomical study, J Hand Surg Br 16:311314, 1991.

12. Gabel GT, Amadio PC, Reoperation for failed decompression of the ulnar nerve in the region of the elbow, J Bone Joint Surg Am 72:213219, 1990.

13. Plancher KD, McGillicuddy JO, Kleinman WB, Anterior intramuscular transposition of the ulnar nerve, Hand Clin 12:435444, 1996.

14. Piyapong Tiyaworanan, Surut Jianmongkol, Tala Thammaroj et al. Anatomical Study of Arcade of Struthers. Hand Surgery.2010; 15(3): 157-159

15. Li MXL, He Q, Hu ZL, Chen SH, Lv YC, Liu ZH, Wen Y, Peng TH (2015) Applied anatomical study of the vascularized ulnar nerve and its blood supply for cubital tunnel syndrome at the elbow region. Neural Regen Res 10(1):141-145.

\section{Source of Support: None Declared} Conflict of Interest: None Declared 